\title{
Determination of Tensile Shear Strength and Corrosion Behavior of Circular Bead Produced by a Laser Beam for Overlapped AISI 304 Steel Sheets
}

Deisi Vieira ${ }^{1}$, Jose Eduardo May ${ }^{2}$, Graziela da Silva Savonov ${ }^{2}$, Rafael Humberto Mota de Siqueira ${ }^{1}$, Milton Sérgio Fernandes de Lima ${ }^{1 *}$ (D)

${ }^{1}$ Instituto de Estudos Avançados - IEAv, São Jose dos Campos, SP, Brasil.

${ }^{2}$ Instituto Nacional de Pesquisas Espaciais - INPE, São José dos Campos, SP, Brasil.

How to cite: Vieira D, May JE, Savonov GS, Siqueira RHM, Lima MSF. Determination of tensile shear strength and corrosion behavior of circular bead produced by a laser beam for overlapped AISI 304 steel sheets. Soldagem \& Inspeção. 2021;26:e2614. https://doi.org/10.1590/0104-9224/SI26.14

\begin{abstract}
A circular bead produced by a laser beam (CLW) is a method of joining superposed sheets by scanning circularly a laser beam. Among the various applications, it could be highlighted the welding of austenitic stainless steel AISI 304 sheets for heat exchangers. This work aims to report the effect of fiber laser CLW in tensile shear strength of superposed sheets as well as the corrosion behavior in relation to the process parameters. It was carried out circular beads using stainless steel AISI 304 sheets varying the laser power and speed. The samples were then submitted to optical and electronic microscopy, tensile-shear tests and electrochemical experiments. Among the experimental conditions, the weld sample with $800 \mathrm{~W}$ power and $50 \mathrm{~mm} / \mathrm{s}$ speed presented an ultimate tensile strength of $159 \mathrm{MPa}, 17 \%$ higher than the sample with the lowest result. The corrosion rate, corrosion and pitting potentials did not change significantly in the welded joint with different conditions compared to the base metal.
\end{abstract}

Keywords: Laser beam welding; Austenitic stainless steel; Tensile strength; Corrosion.

\section{Introduction}

The pillow-plate heat exchangers (PPHE) are characterized by their wavy "pillow-like" surface and discrete circular welds spaced allowing the desired heat transfer. They represent promising alternatives to conventional heat exchangers and are commonly encountered as condensers in the process industry. They are manufactured by inflating the space between two metal sheets which are spot welded to each other, either by laser beam welding (LBW) or electric resistance welding (ERW), and then sealed at the edges (other than the connecting ports) by roll seam welding [1].

High-power fiber lasers have been developed with attractive characteristics for materials processing applications. High-power fiber lasers with high beam quality can produce higher peak power density, which is important for circular bead produced by a laser beam (CLW) with long focal length. Based on several studies, high-power fiber lasers have multiple advantages, such as:

- High electric efficiency;

- $\quad$ Excellent beam quality;

- Relatively low operational costs due to the long lifetime;

- High flexibility in production because of the fiber delivery;

- High absorption coefficient for thin sheets of most alloys;

- Compact design and convenient ergonomics [2].

In the laser beam welding (LBW) several parameters must be considered, such as the power, laser speed, process gases, the distance between the plates to be welded, focal length, among others, which considerably modify the results obtained in the welds. For each material there are welding procedures that improve the results of the process. Therefore, studies that identify these parameters are relevant to a scientific and technological development, since they promote qualitative and quantitative improvements in LBW [3]. Laser beam-induced fusion allows selective heating and melting of the surface, which modifies the surface properties of the material due to rapid melting followed by rapid solidification. The high cooling rates to which this surface layer is subjected results in the formation of different microstructures from the bulk metal, leading to improved properties such as better resistance to wear and corrosion [4]. 
Tran et al [5] review the concept of PPHE including the effect of spot geometry on the heat exchange area. According to the authors, the welding point diameters are chosen as small as possible, still providing the necessary mechanical stability for the sheet during the hydroforming process and the subsequent long-term usage of the pillow. Reducing the welding point diameter improves heat transfer and decreases the pressure loss. As reported, the weld spot diameter varies between 8 and 12 $\mathrm{mm}$. However, these authors did not consider the effects of spots on mechanical and corrosion resistance of PPHE.

Concerning the corrosion resistance, the data reported in the literature vary significantly from about 1 to $20 \mu \mathrm{m} / \mathrm{year}$. As an example, Table 1 [6 - 9], shows, the corrosion rates for AISI 304/304L stainless steel, measured by weight loss immersion tests in seawater environments. Regarding the corrosion rate results there is no significant difference from the values obtained for base metal AISI 304 stainless steel and similar joint AISI 304/304 laser welded.

Table 1. Corrosion rates reported for AISI 304/304L stainless steel (SS).

\begin{tabular}{|c|c|c|c|}
\hline Author & SS Type & Solution & Corrosion Rate ( $\mu \mathrm{m} /$ year) \\
\hline King and Watson [2010] [6] & 304L & Seawater & 11.4 \\
\hline Malik et al. [1994] [7] & $304 L$ & Seawater & 1.2 \\
\hline Haiser and Soo [1995] [8] & 304 & Seawater & 18 \\
\hline UI-Hamid et al. [2017] [9] & 304 & Seawater & 1.1 \\
\hline
\end{tabular}

The purpose of this study is to weld overlapped 304 stainless steel sheets through CLW process, to analyze microstructural, mechanical and corrosion resistance for possible applications in PPHE. Due to the lack of references about inflating characteristics and in-service behavior of stainless steel PPHE, the properties will be compared to the base material.

\section{Materials and Methods}

AISI 304 stainless steel sheets, with dimensions $100 \mathrm{~mm}, 20 \mathrm{~mm}$ and $1 \mathrm{~mm}$, were submitted to circular welds of overlapping joints. This alloy has been chosen for many PPHE components due to its good corrosion resistance. The chemical composition of the material is described in Table 2. The chemical composition is given by the manufacturer's quality certificate.

Table 2. Chemical Composition of Stainless-Steel sheets 304. Fe is the balance.

\begin{tabular}{cccccccccccc}
\hline Composition & $\mathbf{C}$ & $\mathbf{M n}$ & $\mathbf{S i}$ & $\mathbf{P}$ & $\mathbf{S}$ & $\mathbf{C r}$ & $\mathbf{N i}$ & $\mathbf{M o}$ & $\mathbf{T i}$ & $\mathbf{C u}$ & $\mathbf{C o}$ \\
Weight \% & 0.044 & 1.170 & 0.360 & 0.0324 & 0.0011 & 17.78 & 8.00 & 0.106 & 0.0021 & 0.1790 & 0.209 \\
\hline
\end{tabular}

The welding process was performed using a continuous Yb:fiber laser IPG model YLR-2000, with $2.0 \mathrm{~kW}$ of average power, and beam quality $\left(\mathrm{M}^{2}\right)$ approximately 12 , i.e., approximately Gaussian intensity distribution. The beam quality was measured using an OPHIR LT665 camera and related software analyses. The focal length was $160 \mathrm{~mm}$, resulting in a focal diameter of $1 \mathrm{~mm}$ on the surface of the AISI 304 stainless steel sheets. The focus was maintained on the surface of the upper plate. The plates were moved through a CNC table with a resolution of $5 \mu \mathrm{m}$. The speed, $\mathrm{S}$, is the circumferential speed obtained by programming the CNC table. There was no gas protection for the process to be like that of the manufacturing industry called remote laser welding (RLW) [2]. Each sheet was cut in slabs of $200 \mathrm{~mm} \times 20 \mathrm{~mm}$ and superposed by $20 \mathrm{~mm}$ each side. A special clamp fixed the slabs and allow a $6 \mathrm{~mm}$ Circular Bead Produced by a Laser Beam (CLW) from one side of the coupons.

The welding conditions are summarized in Table 3 . The last column on the right of Table 2 is the heat input (HI) as the power of velocity ratio, ranging from 16.0 to $26.7 \mathrm{~J} / \mathrm{mm}$. These values were obtained from the previous experience of the Laboratory of Development of Applications of Lasers and Optics (DEDALO) of Institute for Advanced Studies (IEAv). Outside these optimized conditions, the open air welds present undercuts, porosities and irregular borders.

Table 3. Welding Parameters: Power (P), Laser Speed (S) and Heat Input (HI).

\begin{tabular}{ccccc}
\hline Condition & $\mathbf{P}(\mathbf{W})$ & $\mathbf{S}(\mathrm{m} / \mathrm{min})$ & 2.4 & 20.0 \\
I & 800 & 900 & 2.4 & 2.5 \\
II & 700 & 2.4 & 17.5 \\
III & 800 & 3.8 & 26.7 \\
IV & 800 & 3.0 & 16.0 \\
V & 900 & \\
\hline
\end{tabular}

The microstructural analyses were obtained by means of optical microscopy using a light optical microscope (ZEISS Axion Image.A2m) and a scanning electron microscope (Tescan Vega 3). The samples were cut, sanded and polished with $0.3 \mu \mathrm{m}$ 
diamond suspension and etching was electrolytic using $10 \%$ oxalic acid in water with 4 volts for one minute. The hardness results of the selected regions were obtained by Vickers hardness testing (Future-Tech microdurometer model FM-700) with loading of $100 \mathrm{gf}$ and indentation time of $10 \mathrm{~s}$. Each zone was tested six times with an average distance between the indentations of $100 \mathrm{~mm}$.

The uniaxial shear tensile tests were performed on a universal test machine (EMIC DL model with 100 kN capacity), with a bench speed of $1.0 \mathrm{~mm} / \mathrm{min}$ at room temperature, according to the ASTM E8 standard. The load and strain values were converted to strain and overlap stress for each weld condition. For the calculation of the spot area was considered $A=\pi(D / 2)^{2}$, $D$ being the external diameter.

For the corrosion tests, the instrument used was a potentiostat AUTOLAB. The samples were polished using silicon carbide sandpaper up to 1200 grade in order to obtain the same roughness for all samples. The exposed area of the samples was $0.283 \mathrm{~cm}^{2}$. Electrochemical measurements, potentiodynamic polarization curves, of the base metal and the weld zones were performed in $3.5 \% \mathrm{NaCl}$ aqueous solution in air. A saturated calomel electrode (SCE) at $25^{\circ} \mathrm{C}$ was used as the reference electrode and a platinum rod as the counter electrode for measurement. An open circuit potential (OCP) for each sample was run for 60 minutes. Subsequently, a linear scanning voltammetry (LSV) was performed at $200 \mathrm{mV}$ below the OCP of the material to a suitable voltage with a scan rate of $1 \mathrm{mV} / \mathrm{s}$. The corrosion rate was obtained by the Tafel method. Pitting and corrosion potentials were also obtained.

\section{Results and Discussion}

Figure 1a shows the samples in the five welding conditions (Table 3). Figure $1 \mathrm{~b}$ shows a given Circular Bead Produced by a Laser Beam (CLW), and how the external diameter (D) of the CLW was measured. Despite the different welding parameters, the diameter D varied from 6.1 to $6.7 \mathrm{~mm}$. It implies that the experimental values used in this study do not have a great effect on the welding circle diameter.

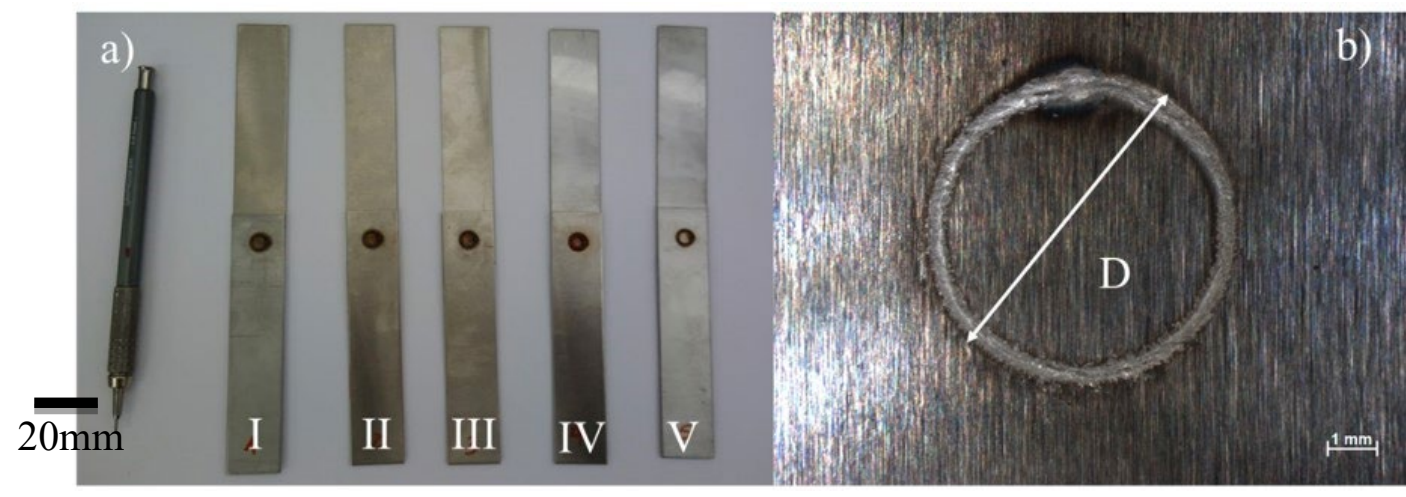

Figure 1 - a) As-welded samples with parameters defined in Table 1; b) Macroscopy of a circular bead produced by a laser beam.

\subsection{Microstructural analyses of the weld beads}

Figure 2 presents a composition of cross-sectional images obtained for conditions from I to $\mathrm{V}$. As can be seen the fusion zone (FZ) shape is similar and typical of keyhole welding. The cross sections were obtained at the circle diameter (Figure 1b) assured by an electron discharge machine.

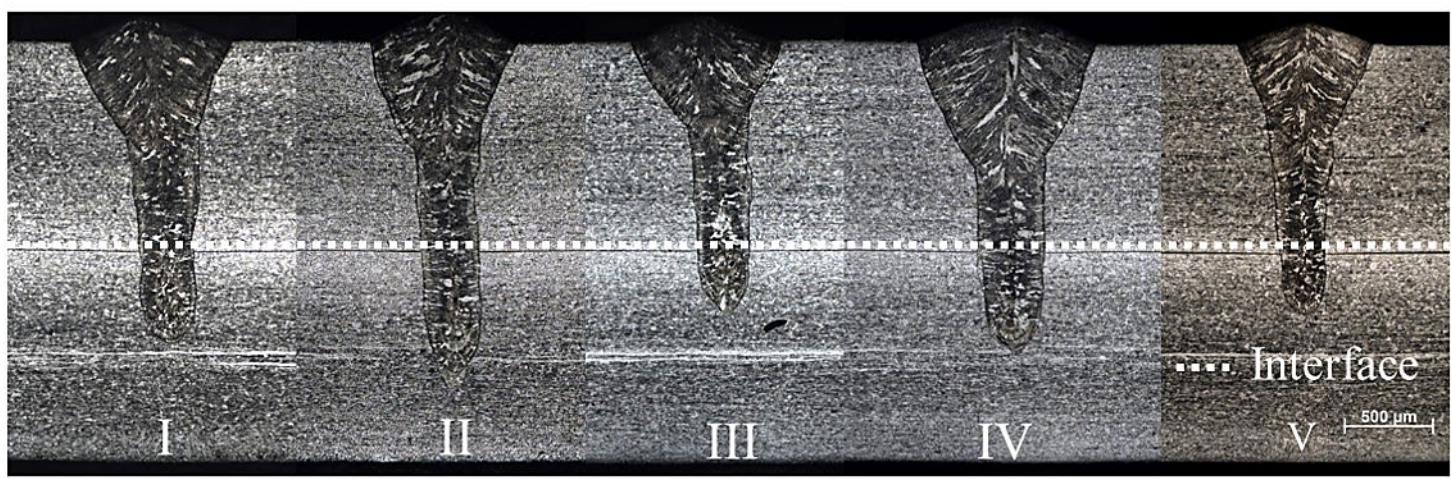

Figure 2. Photocomposition of the cross-section macrographies for the conditions I to V. 
The dimensions change according to the heat input in each case, being the more important to the present case the melt depth and the bead width at the interface between the sheets. These values are presented in Figure 3 as a function of HI. Only a single measured was carried out for each $\mathrm{HI}$.

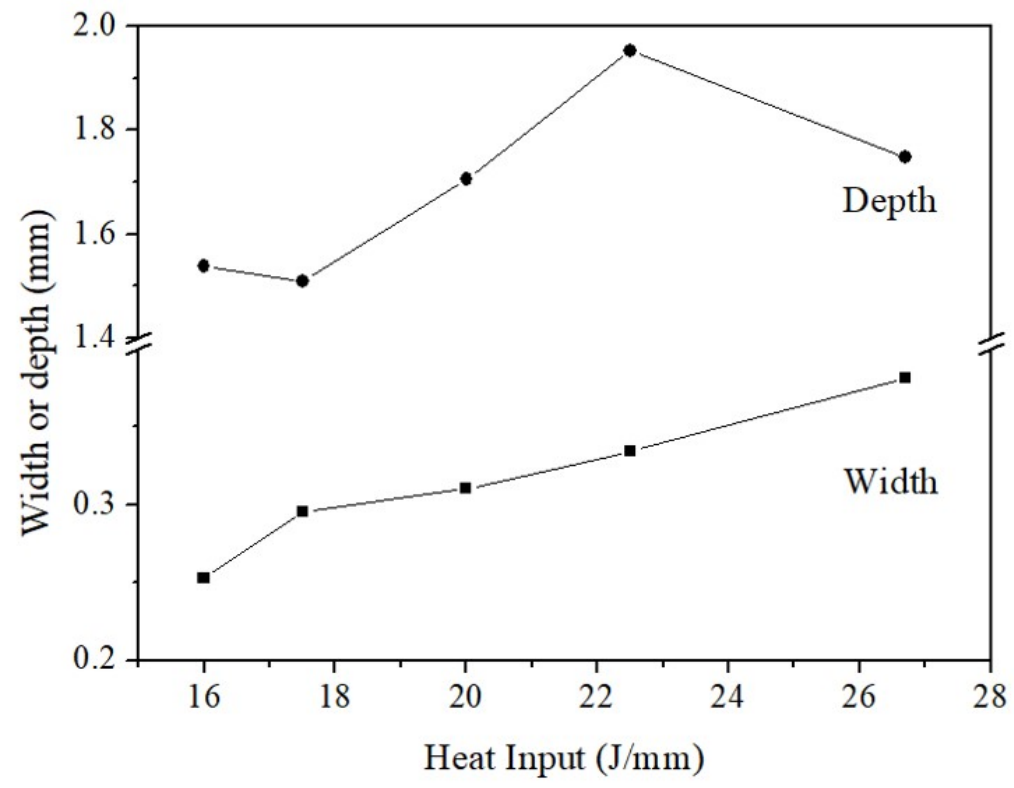

Figure 3. Depth of the fusion zone and the bead width at the interface between the sheets as a function of the heat input ( $\mathrm{HI})$.

The weld width follows an approximately raising curve with increasing $\mathrm{HI}$, however the melt depth is less confident. The explanation could be linked to the plasma effect [10]. For example, the depth observed for $\mathrm{HI}=26.7 \mathrm{~J} / \mathrm{mm}$ (Cond. IV) is $1.7 \mathrm{~mm}$ compared to $1.9 \mathrm{~mm}$ for $\mathrm{HI}=22.5 \mathrm{~J} / \mathrm{mm}$ (Cond. II). When the laser speed is relatively low, e.g. $1.8 \mathrm{~m} / \mathrm{min}$, the plasma residence time is higher and absorbs more incident radiation lasting less energy for the keyhole [11]. Nevertheless, all conditions produced a penetrating sufficient to join the sheets exceeding $1 \mathrm{~mm}$ of the upper sheet. The widths at the interface (Figure 3) lie between 0.25 and $0.38 \mathrm{~mm}$ providing sufficient mechanical attachment to resist the hydraulic pressure of PPHE [12].

Figure 4 shows the austenitic microstructure and the interface between the sheets after welding (Cond. I). The space between the sheets are partially filled with liquid metal (arrow in Figure $4 b$ ) as a result of capillarity effect during the melting of the weld bead.
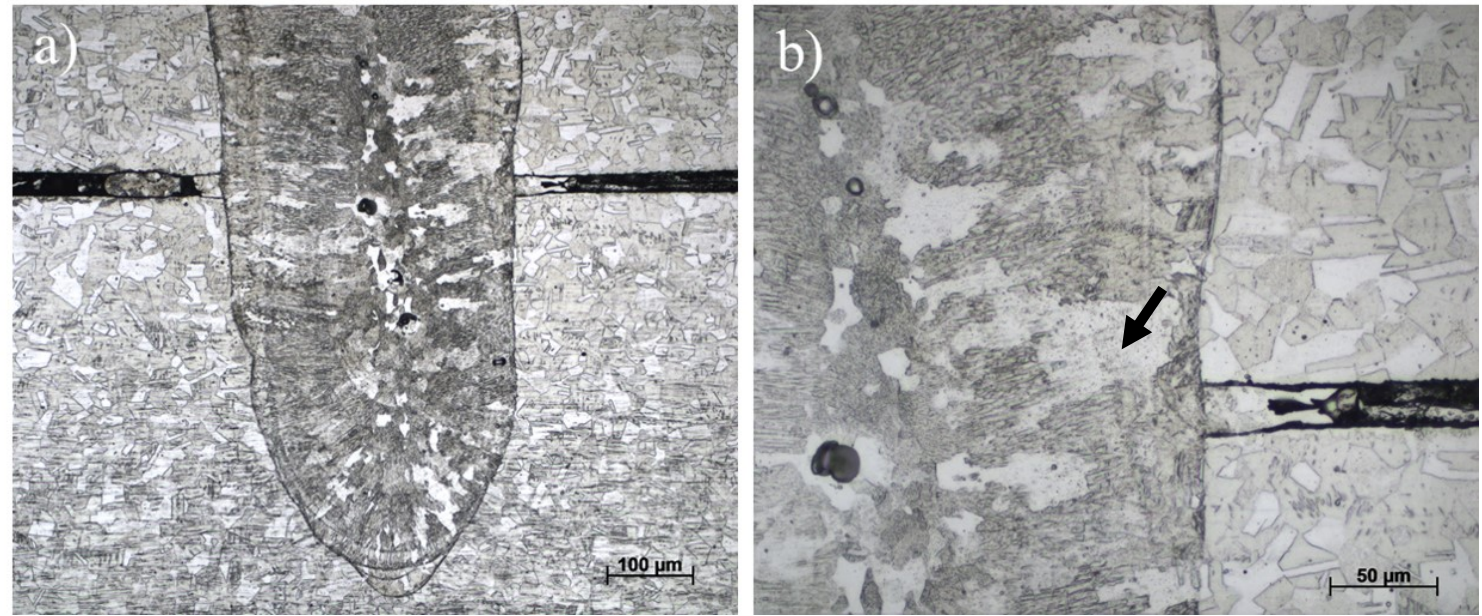

Figure 4. a) Region of the weld root (Cond. I); b) Central region of the weld (Cond. I).

Figure 4a details the growth of columnar grains. Some pores has been found, but is a shrinkage resulting from the differences in density between liquid and solid and the evolution of dissolved gases and is not attributed to the laser welding itself. On the other hand, the pore near to the weld center (Figure 4) could be attributed to some entrapped gases during the 
keyhole evolution. These pores are very small and occasional and do not present a threat to the join integrity. Figures $5 \mathrm{a}$ and $5 \mathrm{~b}$ detail the regions of the base metal (BM), heat affected zone (HAZ) and fusion zone (FZ) for condition I. All the other conditions presented similar features.
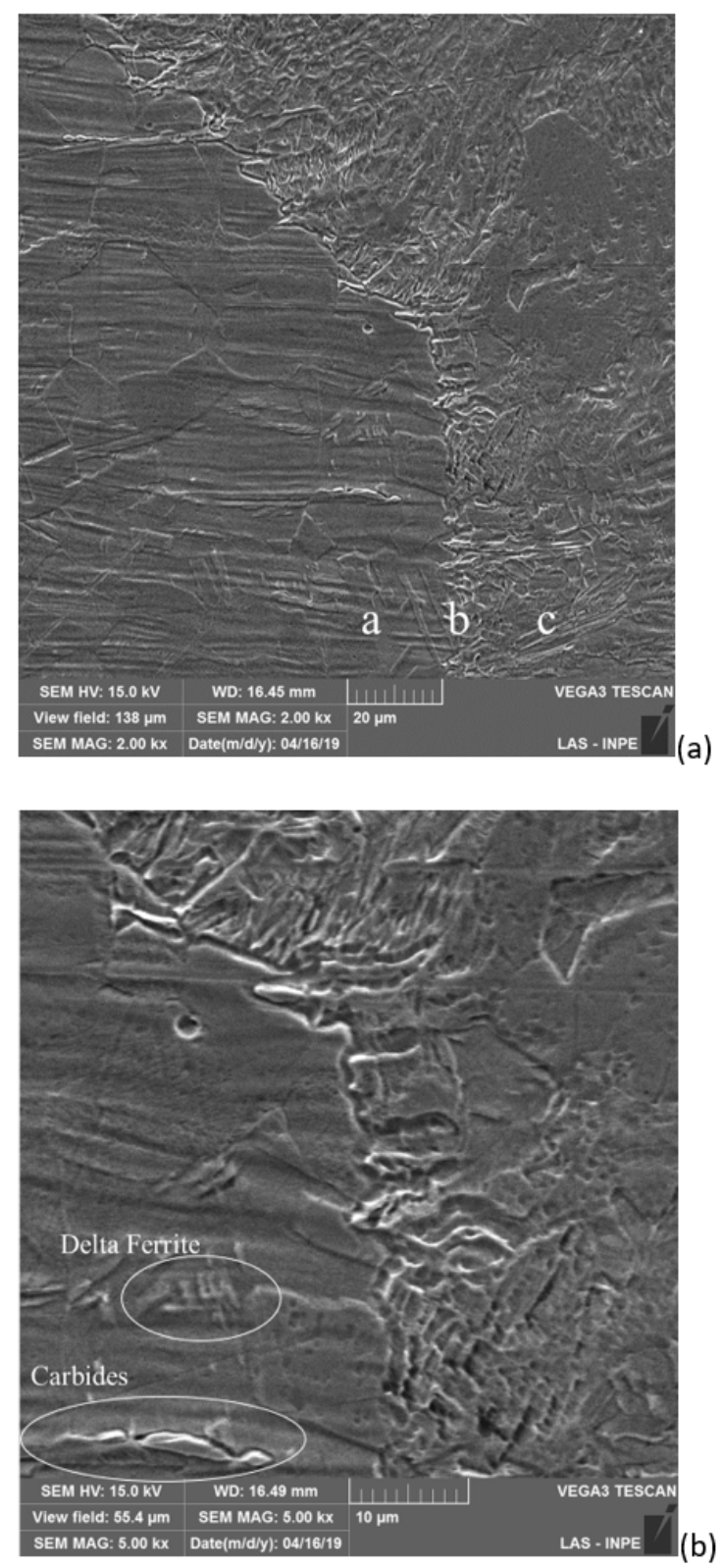

Figure 5. SEM region with formation of delta ferrite and carbides (Condition I): $a$ ) legend $a=H A Z, b=i n t e r f a c e, c=F Z ; b)$ zoom near to the precipitation zone.

The only observed microstructural change is refined and uniformly oriented austenite dendrites. Dendritic growth follows substrate grain direction, dendrites can reach the surface with no or minimum disruption by their neighbors, thus resulting in a more uniformly oriented structure [4]. In the region of the base metal was identified the formation of ferrite and carbides. The presence of $10 \%$ of ferrite is predicted by the Schaeffler diagram [13]. On the other hand, the presence of some aligned carbides (Figure 5) could result in some degree of sensitization at the heat-affected zone (HAZ) as already reported in the literature [21]. The carbide precipitates were not observed in condition $\mathrm{V}$ (low heat input), and therefore the critical heat input for sensitization, under the current experimental conditions, was between 16 and $20 \mathrm{~J} / \mathrm{mm}$.

\subsection{Mechanical analyses}

Table 4 presents the results of the hardness test in BM, HAZ and FZ for each condition. 
Table 4. Results of the hardness test (Vickers) of the BM, HAZ and FZ.

\begin{tabular}{lccccccc}
\hline & & \multicolumn{4}{c}{ CONDITION } \\
\cline { 3 - 7 } & & I & II & III & IV & V \\
Average $(H V)$ & BM & $222 \pm 8$ & $216 \pm 0$ & $220 \pm 10$ & $207 \pm 10$ & $221 \pm 5$ \\
Average (HV) & HAZ & $208 \pm 14$ & $222 \pm 10$ & $216 \pm 9$ & $217 \pm 8$ & $216 \pm 11$ \\
Average (HV) & FZ & $207 \pm 11$ & $225 \pm 10$ & $207 \pm 15$ & $215 \pm 5$ & $203 \pm 5$ \\
\hline
\end{tabular}

The hardness of base AISI 304 stainless steel is approximately $200 \mathrm{HV}$. As can be seen in Table 4, any change in hardness values of the BM, HAZ and FZ were observed. This result diverges with that presented by L. Zhang et al [14], since there was no formation of phases that would increase the hardness in the molten zone such as delta ferrite. Additionally, the laser process did not induce strain-hardening effects as sometimes observed in the welding of ductile metallic materials.

Figure 6 shows the strain tensile results for the five welding conditions. The tensile stress curves presented three conditions with higher stress values. Conditions I, II and IV, with stress values close to $155 \mathrm{MPa}$, presented large ductility compared to condition $\mathrm{V}$. The worst conditions have the lowest laser power value $(700 \mathrm{~W})$ and the highest speed of the laser beam $(\mathrm{S}=50 \mathrm{~mm} / \mathrm{s})$.

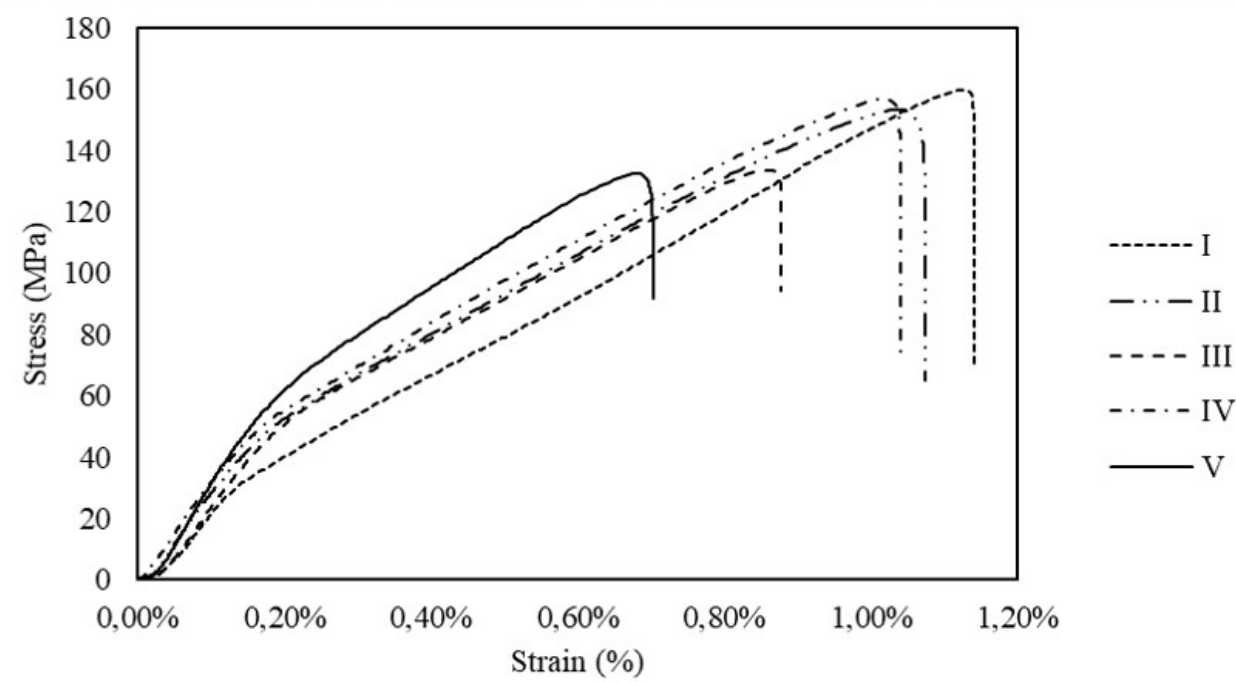

Figure 6. Stress $x$ Strain curves for the five welding conditions.

Table 5 presents the results for the ultimate tensile stress (UTS) for each condition and compares to HI. As can be seen, UTS varies almost linearly with $\mathrm{HI}$ and those coupons that presented the bead width at the interface above $310 \mu \mathrm{m}$ (Figure 3 ) exceeds $153 \mathrm{MPa}$ UTS.

Table 5. Ultimate tensile strength (UTS) values and bead width for each welding condition.

\begin{tabular}{ccc}
\hline CONDITION & HI $(\mathrm{J} / \mathrm{mm})$ & UTS (MPa) \\
I & 20.0 & 159 \\
II & 22.5 & 153 \\
III & 17.5 & 133 \\
IV & 26.7 & 156 \\
V & 16.0 & 132 \\
\hline
\end{tabular}

\subsection{Corrosion}

Figure 7 shows the polarization curves for the base metal AISI 304 stainless steel compared with the similar joint AISI $304 / 304$ laser welded in different conditions of laser power and welding speed. 

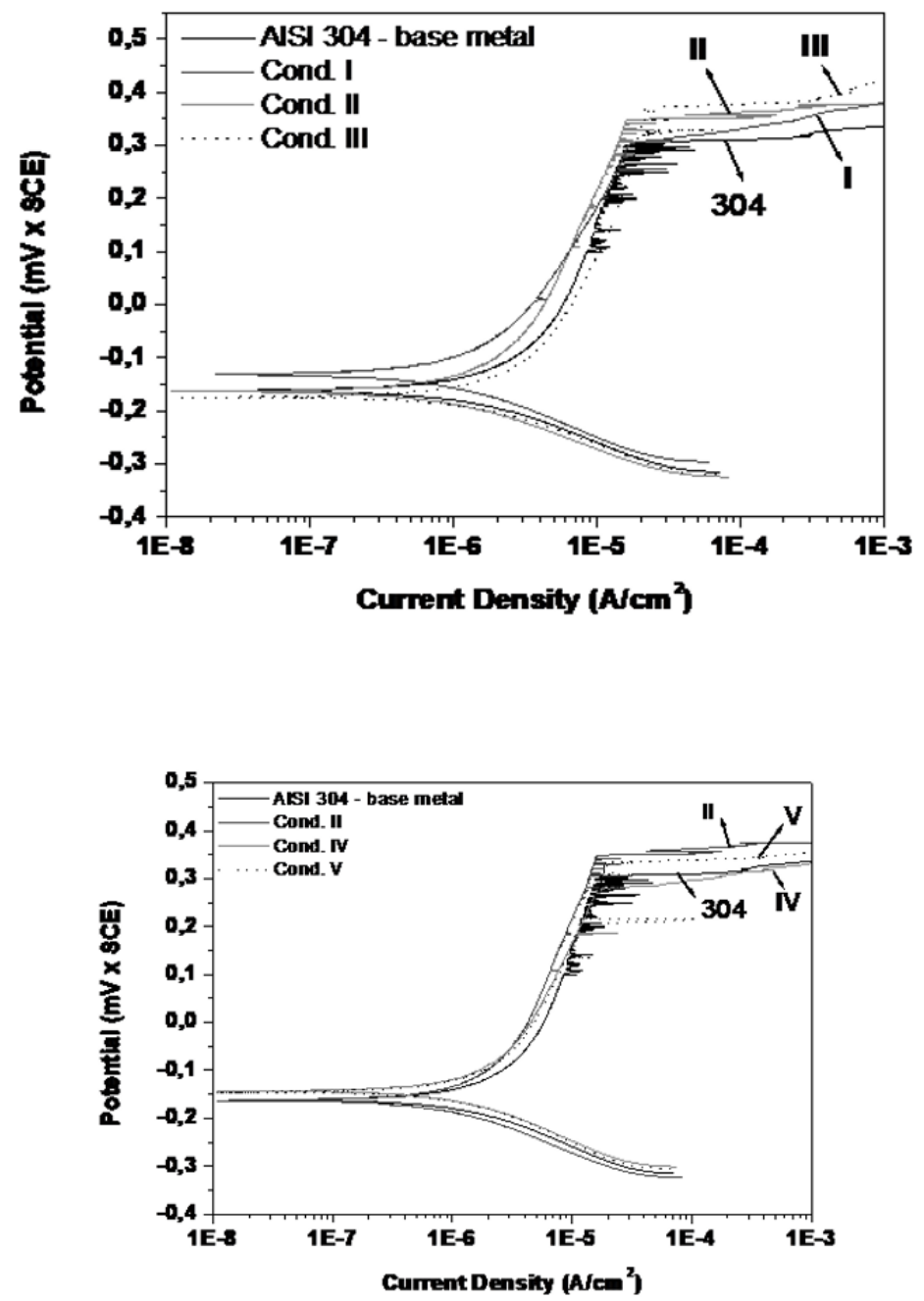

Figure 7. Polarization curves in $\mathrm{NaCl} 3.5 \%$ for the base metal AISI 304 stainless steel and similar joint AISI 304/304 laser welded in different conditions of laser power and welding speed.

Figures 8 and 9 show the corrosion and pitting potentials, respectively, extracted from the polarization curves. The results showed not a significant difference from pitting potentials of the base metal AISI 304 stainless steel and similar joint AISI $304 / 304$ laser welded, given the overlap between the error bars.

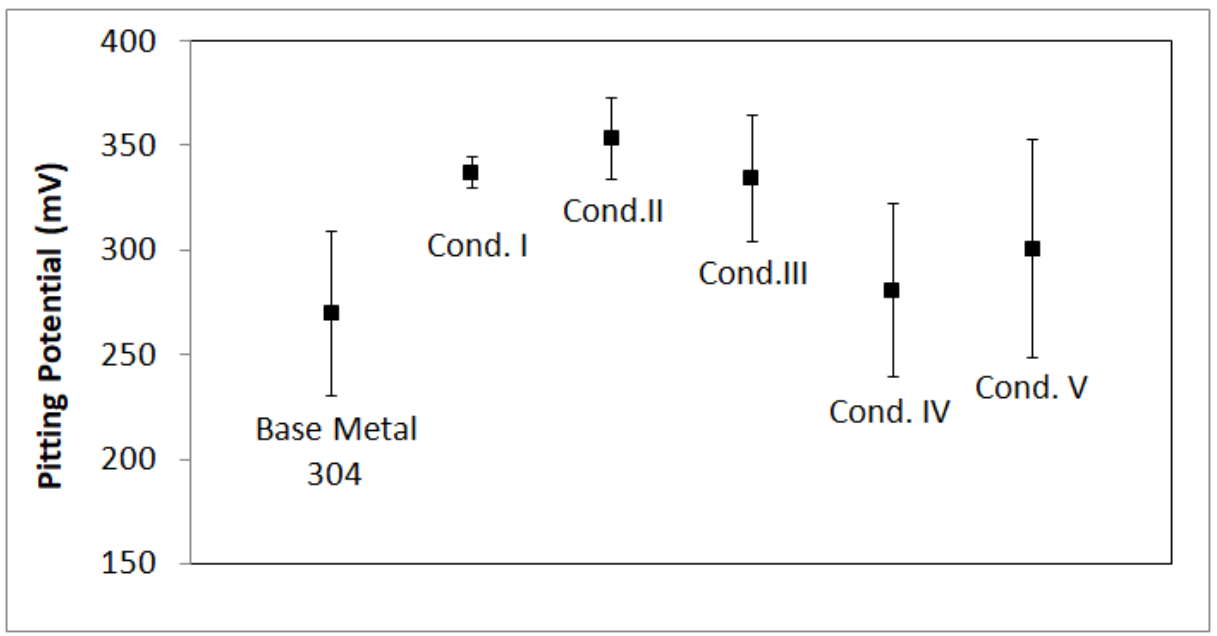

Figure 8. Pitting potentials, extracted from the polarization curves. 


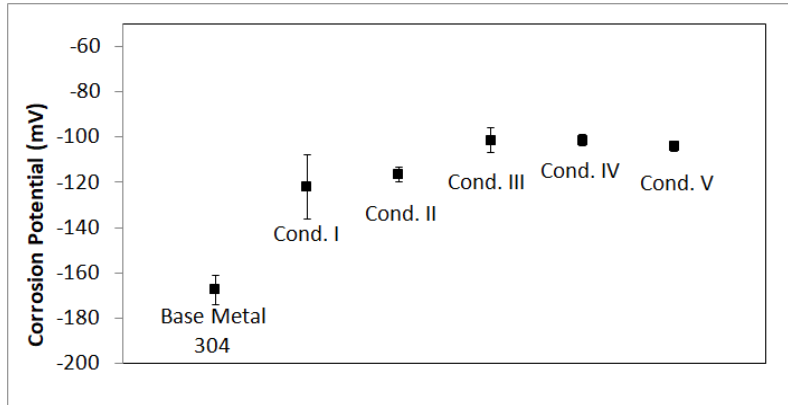

Figure 9. Corrosion potentials, extracted from the polarization curves.

Table 6 shows the data extracted from the electrochemical measurements in laser welded joints obtained for some authors. The authors present the corrosion and pitting potential for the base metal (BM - AISI 304), for the heat affected zone (HAZ) and welding zone (WZ). Additionally, also present the current of corrosion or the corrosion rate for them. Therefore, these parameters vary from 0.001 to $2500 \mu \mathrm{m} /$ year, which is not a good agreement with the real immersion corrosion rate. All the electrochemical experiments were conducted in $\mathrm{NaCl} 3,5 \%$ solution, with scan rate of 0.5 to $1 \mathrm{mV} / \mathrm{s}$ and with the SCE reference electrode (or with $\mathrm{Ag} / \mathrm{AgCl}$ which were converted to SCE potential) and the potentials were extracted from the polarization curves and the corrosion values were obtained from the Tafel method evaluation.

Table 6. Data extracted from the electrochemical measurements in laser-welded joints.

\begin{tabular}{|c|c|c|c|c|}
\hline Author & $\begin{array}{l}\text { Ecorr } \\
(\mathrm{mV})\end{array}$ & $\begin{array}{l}\text { Epit } \\
\text { (mV) }\end{array}$ & $\begin{array}{l}\text { Corr. Rate } \\
\text { ( } \mu \mathrm{m} / \text { year) }\end{array}$ & Obs. \\
\hline & -522 & 500 & 0.4 & WZ \\
\hline \multicolumn{5}{|l|}{ Zhang et al. [2013] [15] } \\
\hline & -648 & 250 & 0.2 & HAZ \\
\hline Yazdian et al. [2018] [16] & -250 & 270 & 0.001 & BM \\
\hline Kang et al. [2017] [17] & -250 & 270 & 0.002 & BM \\
\hline & - & - & 2466 & BM \\
\hline \multicolumn{5}{|l|}{ Tash [2015] [18] } \\
\hline & - & - & 249 & WZ \\
\hline J Karlsson [2017] [19] & -52 & 239 & 14.4 & BM \\
\hline P Dhaiveegan et al. [2016] [20] & -150 & 300 & - & BM \\
\hline
\end{tabular}

The observed values of corrosion potential (about $-120 \mathrm{mV}$ ) and pitting potential (about 300mV) for the base metal (BM AISI 304) and welding zone (WZ) are in good agreement with the literature, about $-300 \mathrm{mV}$ in average to corrosion potential and $300 \mathrm{mV}$ in average to pitting potential.

Figure 10 shows the corrosion rate extracted from the polarization curves using Tafel method.

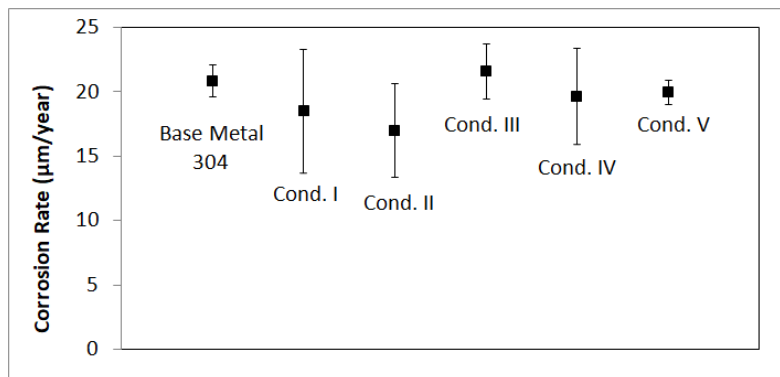

Figure 10. Corrosion rate extracted from the polarization curves using Tafel method in NOVA 2.1 software from AUTOLAB. 
According to the results obtained, the values of the corrosion rates were similar to each other, given the overlap between the error bars. Thus, there is no significant variation between the values obtained for the similar joint AISI 304/304 laser welded and for the base metal AISI 304 stainless steel. The corrosion rate obtained, around $20 \mu \mathrm{m} /$ year, show a good agreement with weight loss immersion tests, about 1 to $20 \mu \mathrm{m} /$ year, according to Table 1 . It is not completely understood why higher laser power conditions slightly increased the pitting susceptibility in FZ in comparison to lower power conditions. According to Pradhan et al. [22] this could be linked to chromium depleted regions (more energy, more time to microsegration takes place) and to the residual stresses (linked to the weld energy).

Figure 11 shows the SEM images for AISI 304 base metal after the polarization measurements. The pittings preferentially grow in the grain boundaries but also in the volume of the grain.

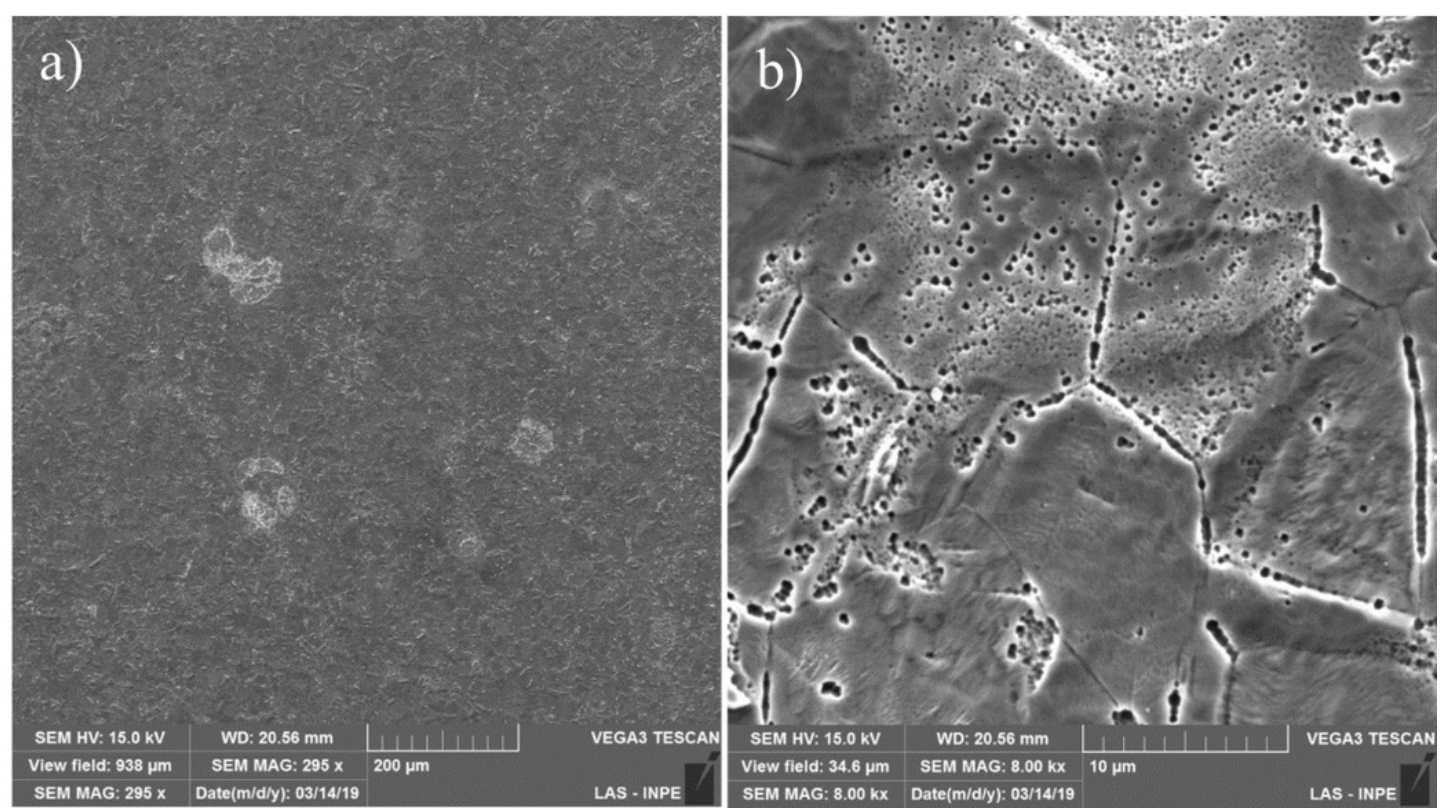

Figure 11. SEM images from AISI 304 showing pits in the base metal: a) fusion zone; b) detail in the fusion zone.

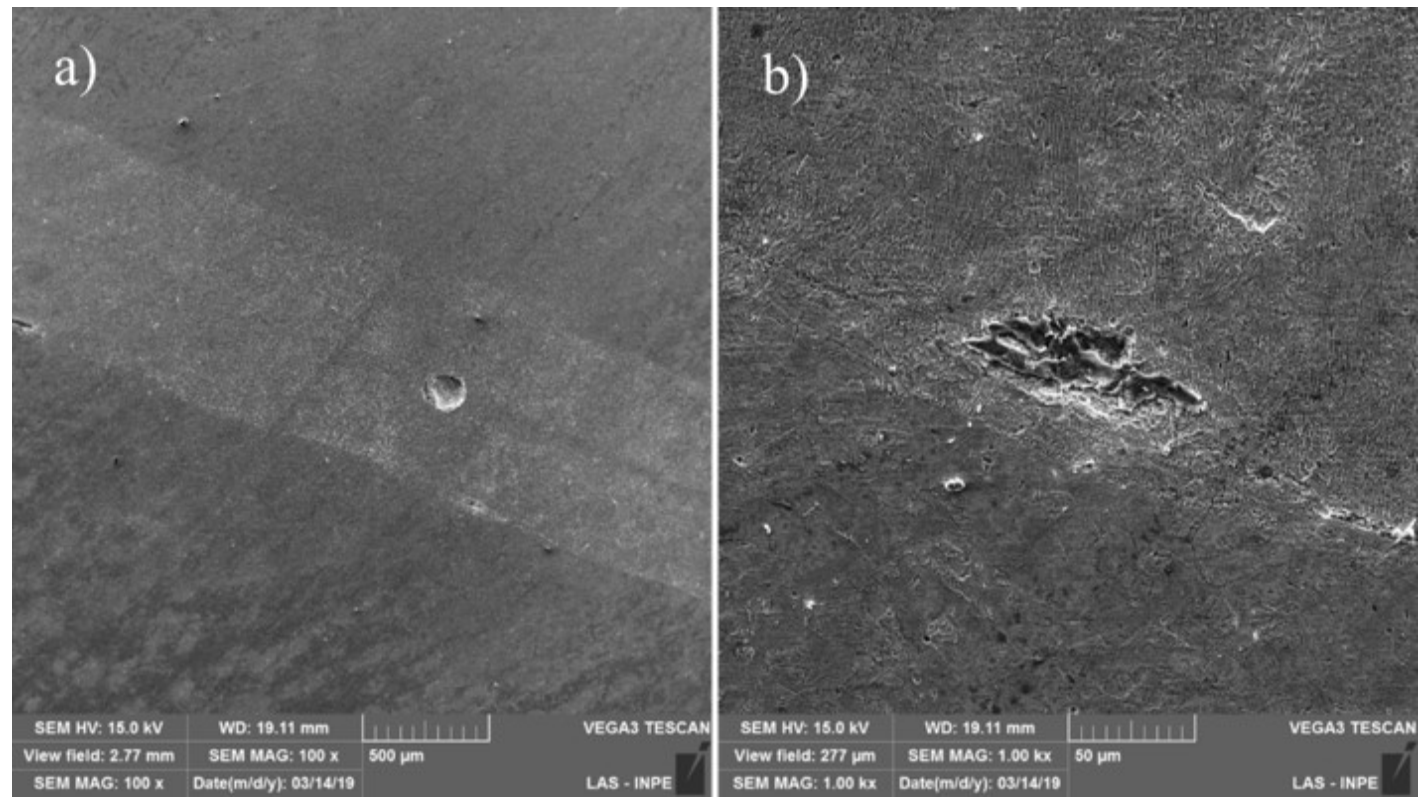

Figure 12. SEM images for condition I: a) fusion zone; b) detail in the fusion zone.

In the condition I, Figure 12, the pits grow preferentially in the middle of FZ. It was also observed the same porosity related with gases concentration and microsegregation. The same behavior was observed for condition II, Figure 13. Therefore, the pits seem to be more intense and deeper than for condition I. It was not observed pits outside welding zone for both conditions. 


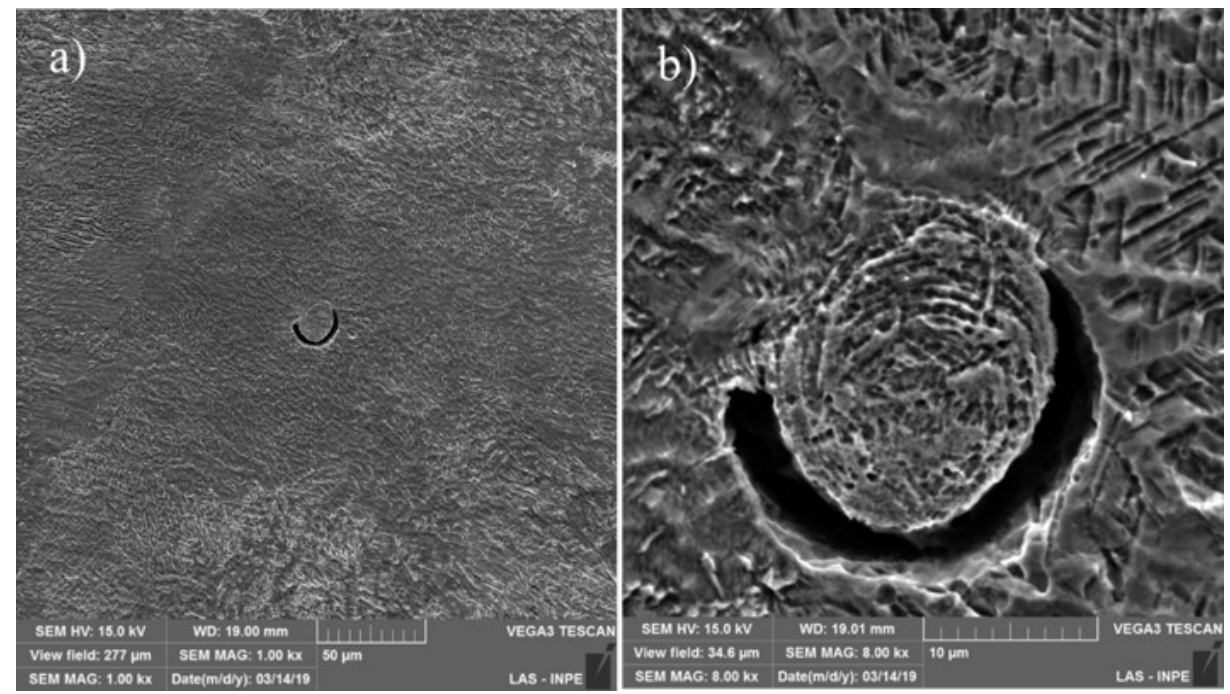

Figure 13. SEM images for condition II: a) fusion zone; b) detail in the fusion zone.

Figure 14 shows the images for condition III. It was observed a shallow pittings in the welding zone and also in the grain boundaries in the base metal. The same behavior was observed in condition IV, Figure 15. The condition V presented only shallow pits in the welding zone, Figure 16.

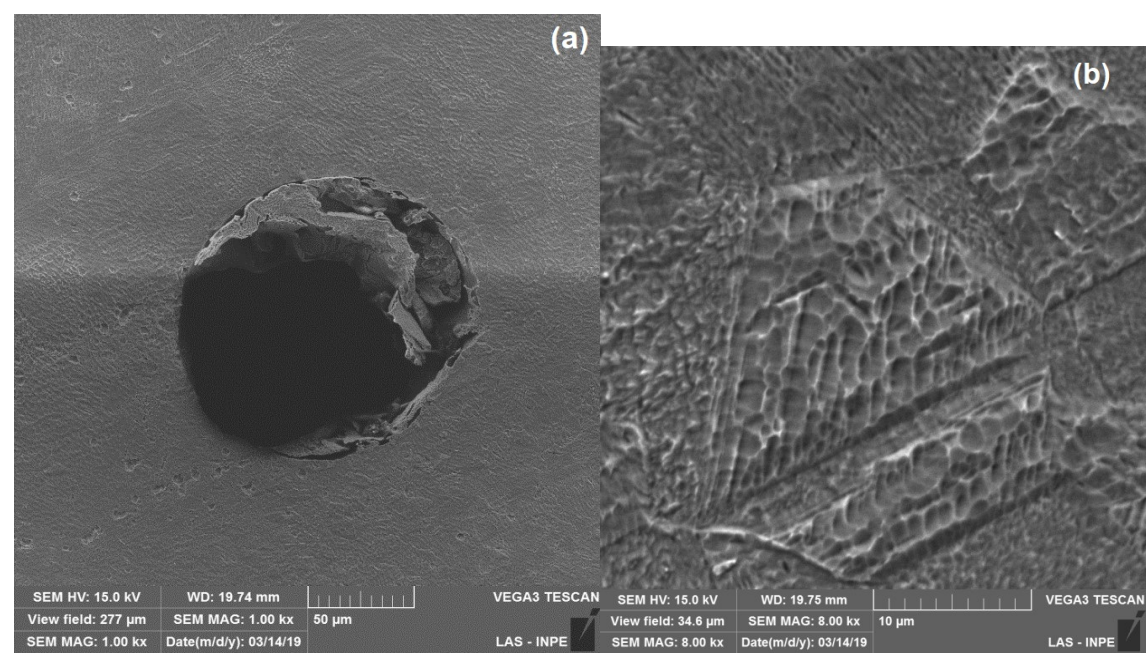

Figure 14. SEM images for condition III: a) welding zone and b) base metal.

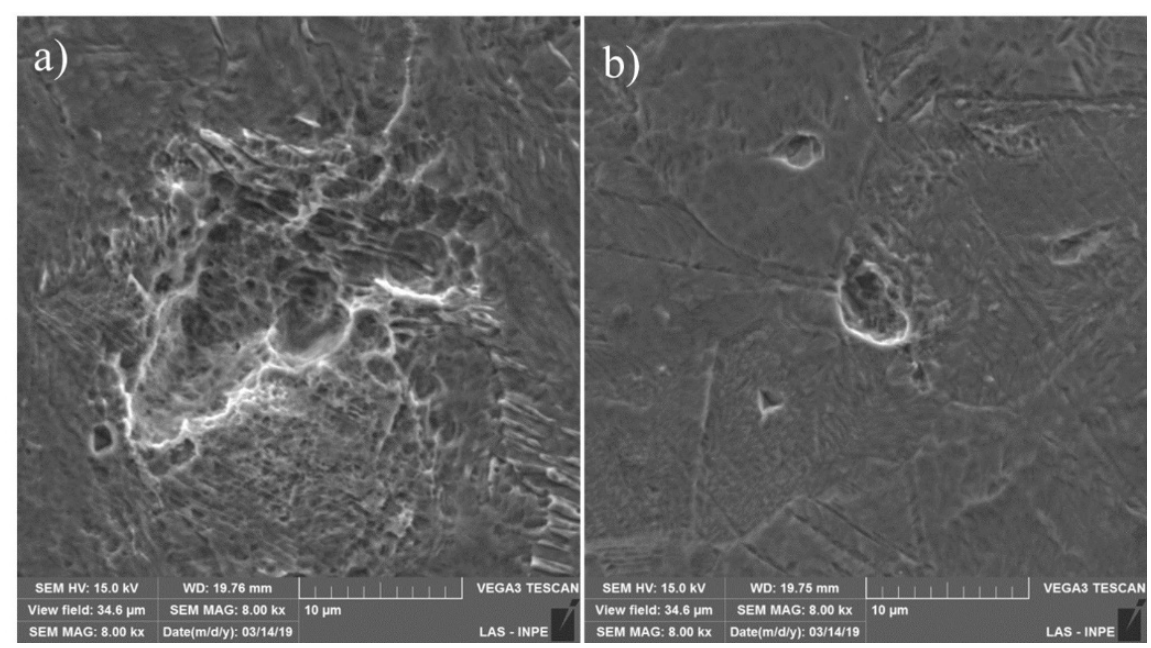

Figure 15. SEM images for condition IV: a) welding zone and b) base metal. 


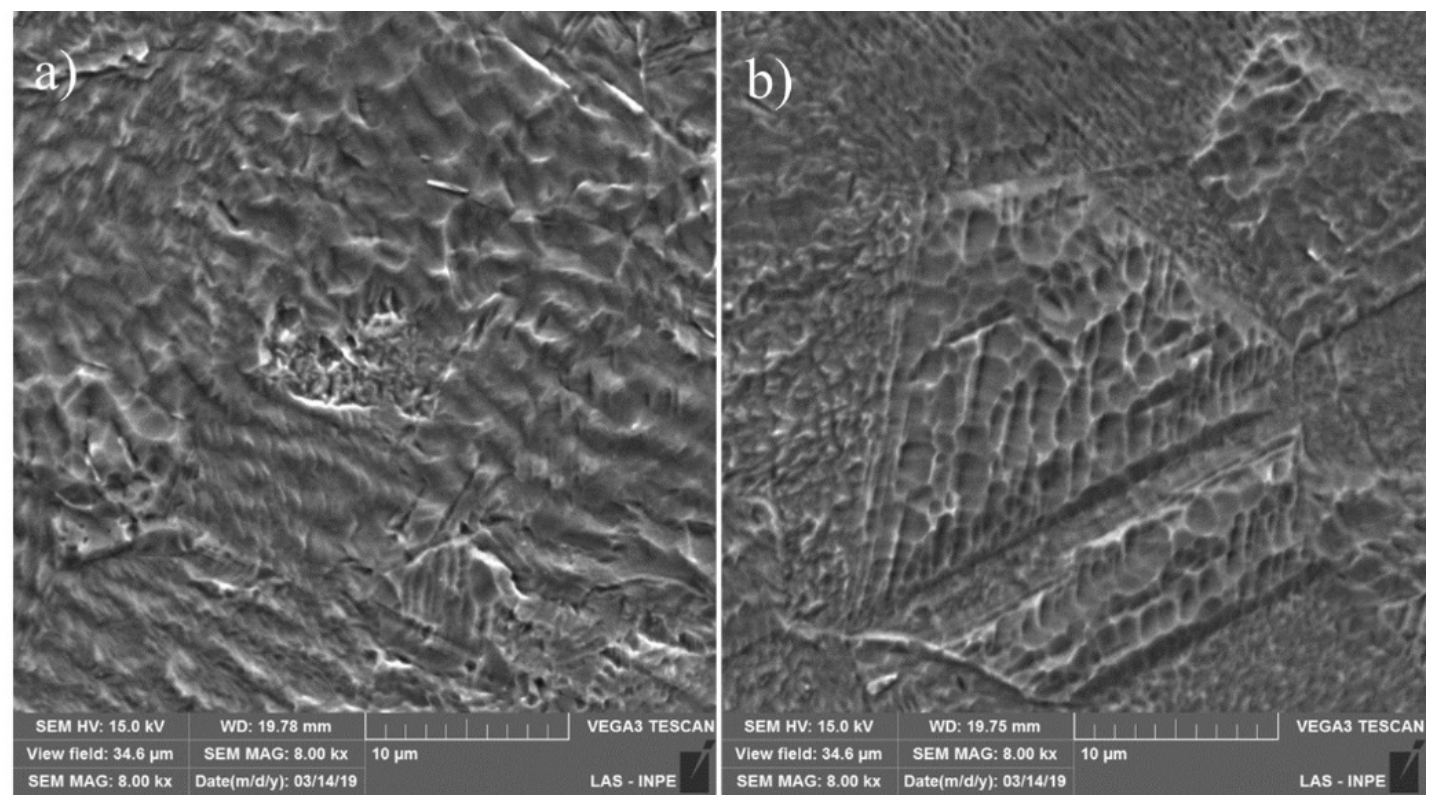

Figure 16. SEM images for condition $\mathrm{V}$ : a) welding zone and b) base metal.

Table 7 summarizes the SEM observed pitting evaluation.

Table 7. SEM observed pitting evaluation.

\begin{tabular}{|c|c|c|}
\hline Condition & Fusion Zone & Base Metal \\
\hline BM & - & Pittings preferentially in the grain boundaries but also in the volume \\
\hline I & Deeper pittings preferentially in the HAZ & No pittings in the base metal \\
\hline II & Deeper pittings in the $\mathrm{FZ}$ & No pittings in the base metal \\
\hline III & Shallow pittings in the FZ & Shallow in the base metal, preferentially in the grain boundaries \\
\hline IV & Shallow pittings in the FZ & Shallow in the base metal, preferentially in the grain boundaries \\
\hline V & Shallow pittings in the FZ & No pittings in the base metal \\
\hline
\end{tabular}

Despite the anodic polarization curves showed not significant change corrosion behavior between the samples, the morphology of the observed pitting changed. The higher laser power intensity ( 800 and $900 \mathrm{~W}$ ) induced the susceptibility to pitting formation in the welding zone. The low power laser intensity and lowest speed reduced the susceptibility to pitting formation in the welding zone.

Analyzing the mechanical and corrosion resistances together, the condition IV presented one of the highest stress values (tensile shear strength) and a better corrosion behavior related with grains morphology. This condition presented an intermediate laser power intensity $(800 \mathrm{~W})$ and the lowest speed laser tested. This condition IV also showed the best combination of depth of the fusion zone and the bead width at the interface.

\section{Conclusions}

After the experimental work, some conclusions could be drawn: 
A partial absence of pores and cracks in the fusion zone (FZ) and in the HAZ was verified in all conditions, although the open air weld condition.

The FZ presented an austenitic microstructure, with columnar or equiaxial grains depending on the location;

The weld sample with $800 \mathrm{~W}$ power and $50 \mathrm{~mm} / \mathrm{s}$ speed presented an ultimate tensile strength of $159 \mathrm{MPa}, 17 \%$ higher than the sample with the lowest result. However, this sample presented a relatively low final elongation, of just $0.71 \%$, because of the lap stress concentration;

The hardness values did not change appreciably from base material, heat-affected zone and fusion zone in the current experimental conditions. The average hardness was approximately $220 \mathrm{HV}$.

The CLW did not change significantly the corrosion behavior of the AISI 304 stainless steel;

The corrosion rate, corrosion and pitting potentials did not change significantly in the welded joint with different laser power and welding speed conditions compared with the base metal.

\section{Acknowledgements}

DV, RHMS and MSFL thanks Coordenação de Aperfeiçoamento de Pessoal de Nível Superior (CAPES) for the support of the Graduate Program in Science and Space Technologies (PG-CTE/ITA). RHMS thanks São Paulo Research Foundation FAPESP for the postdoctoral scholarship (grant\# 2019/25229-7). MSFL also acknowledge the financial support of São Paulo Research Foundation FAPESP grant\# 2016/11309-0 and National Council for Scientific and Technological Development (CNPq).

\section{References}

[1] Piper M, Olenberg A, Tran JM, Kenig E. Determination of the geometric design parameters of pillow-plate heat exchangers. Applied Thermal Engineering. 2015;91:1168-1175. http://dx.doi.org/10.1016/j.applthermaleng.2015.08.097.

[2] Kah P, Lu J, Martikainen J, Suorante R. Remote laser welding with high power fiber lasers. Engineering. 2012;5(9):700-706.

[3] Coelho BN, Lima MSF, Costa AR. Welding of the stainless steel AISI 316 with high power fiber laser: influence of the operational parameters on microhardness and electrolytic corrosion susceptibility of the weld beads. Revista Matéria. 2013;11505:1338-1349.

[4] Cheung NL, Larosa MA, Osório WR, Lima MSF, Lerardi MCF, Garcia A. Numerical simulation and experimental analysis of laser surface remelting of AISI 304 stainless steel samples. Materials Science Forum. 2010;636-637:1119-1124. http://dx.doi.org/10.4028/www.scientific.net/MSF.636-637.1119.

[5] Tran JM, Piper M, Kening EY, Scholl S. Pillow-plate heat exchangers: fundamental characteristics. innovative heat exchangers. Springer: Berlin; 2017. p. 233-245.

[6] King F, Watson S. Review of the Corrosion Performance of Selected Metals as Canister Materials for UK Spent Fuel and/or HLW. In: 4th international workshop on long-term prediction of corrosion damage in nuclear waste systems. (p. 16). Oxfordshire: Quintessa Limited; 2010. Corrosion of Stainless Steels - Appendix F.

[7] Malik AU, Siddiqi NA, Andijani IN. Corrosion behavior of some highly alloyed stainless steels in seawater. Desalination. 1994;97(1-3):189197. http://dx.doi.org/10.1016/0011-9164(94)00086-7.

[8] Haiser JH, Soo P. Corrosion of barrier materials in seawater environments. New York: Brookhaven National Laboratory; 1973.

[9] Ul-Hamid A, Saricimen H, Quddus A, Mohammed Al, Al-Hems LM. Corrosion study of SS304 and SS316 alloys in atmospheric, underground and seawater splash zone in the Arabian Gulf. Corrosion Engineering, Science and Technology. 2017;52(2):134-140. http://dx.doi.org/10.1080/1478422X.2016.1213974.

[10] Shcheglov PY, Gumenyuk AV, Gornushkin IB, Rethmeier M, Petrovskiy VN. Vapor-plasma plume investigation during high-power fiber laser welding. Laser Physics. 2013;23:016001.

[11] Xu J, Luo Y, Zhu L, Han J, Zhang C, Chen D. Effect of shielding gas on the plasma plume in pulsed laser welding. Measurement. 2019;134:25-32. http://dx.doi.org/10.1016/j.measurement.2018.10.047.

[12] Shirzad M, Delavar MA, Ajarostaghi SSM, Sedighi K. Evaluation the effects of geometrical parameters on the performance of pillow plate heat exchanger. Chemical Engineering Research \& Design. 2019;150:74-83. http://dx.doi.org/10.1016/j.cherd.2019.06.032.

[13] Schaeffler AL. Constitution diagram for stainless steel weld metal. Metal Progress. 1949;56(11):680.

[14] Zhang L, Lu JZ, Luo KY, Feng AX, Dai FZ, Zhong JS, et al. Residual stress, micro hardness and tensile properties of ANSI 304 stainless steel thick sheet by fiber laser welding. Materials Science and Engineering. 2013;561:136-144. http://dx.doi.org/10.1016/j.msea.2012.11.001.

[15]Zhang L, Zhang YK, Lu JZ, Dai FZ, Feng AX, Luo KY. Effects of laser shock processing on electrochemical corrosion resistance of ANSI 304 stainless steel weldments after cavitation erosion. Corrosion Science. 66:5-13, 2013.

[16] Yazdian N, Mohammadpour M, Razavi R, Kovacevic R. Hybrid laser/arc welding of 304L stainless steel tubes, part 2 - Effect of filler wires on microstructure and corrosion behavior. International Journal of Pressure Vessels and Piping. 2018;163:45-54.

http://dx.doi.org/10.1016/j.ijpvp.2018.04.005. 
[17] Kang K, Kawahito Y, Gao M, Zeng X. Effects of laser-arc distance on corrosion behavior of single-pass hybrid welded stainless clad steel plate. Materials \& Design. 2017;123:80-88. http://dx.doi.org/10.1016/j.matdes.2017.03.049.

[18] Tash MM. Laser welding of similar stainless steels (304/304) and dissimilar stainless steel (304)/carbon steel (A36) alloys. International Journal of Advanced Technology in Engineering and Science. 2015;3(3):23-43.

[19] Karlsson J. Pitting corrosion on stainless steel with and without passivation [master thesis]. Sweden: Centre for Analysis and Synthesis Lund University; 2017.

[20] Dhaiveegan P, Elangovan N, Nishimura T, Rajendran N. Corrosion behavior of 316L and 304 stainless steels exposed to industrialmarine-urban environment: field study. RSC Advances. 2016;6:47314.

[21] Tiedra P, Martín Ó, López M. Combined effect of resistance spot welding and post-welding sensitization on the degree of sensitization of AISI 304 stainless steel. Corrosion Science. 2011;53(8):2670-2675. http://dx.doi.org/10.1016/j.corsci.2011.05.007.

[22] Pradhan SK, Bhuyan P, Mandal S. Influence of the individual microstructural features on pitting corrosion in type 304 austenitic stainless steel. Corrosion Science. 2019;158:108091. http://dx.doi.org/10.1016/j.corsci.2019.108091. 